\title{
Modelling of nutrient partitioning in growing pigs to predict their anatomical body composition. 2. Model evaluation
}

\author{
V. $\operatorname{Halas}^{1}{ }^{*}$, J. Dijkstra ${ }^{2}$, L. Babinszky ${ }^{1}$, M. W. A. Verstegen ${ }^{2}$ and W. J. J. Gerrits ${ }^{2}$ \\ ${ }^{1}$ University of Kaposvár, Faculty of Animal Science, Department of Animal Nutrition, P. O. Box 16, H-7400 Kaposvár, \\ Hungary \\ ${ }^{2}$ Animal Nutrition Group, Wageningen University and Research Centre, Zodiac, Marijkeweg 40, 6709 PG Wageningen, \\ The Netherlands
}

(Received 3 December 2003 - Revised 15 April 2004 - Accepted 18 May 2004)

\begin{abstract}
The objective of the present paper was to evaluate a dynamic mechanistic model for growing and fattening pigs presented in a companion paper. The model predicted the rate of protein and fat deposition (chemical composition), rate of tissue deposition (anatomical composition) and performance of pigs depending on nutrient intake. In the model evaluation, the predicted response of the pig to changes in model parameters and to changes in nutrient intakes is presented. As a result of the sensitivity analysis, changes in the maintenance energy requirements and the fractional degradation rate of muscle protein had the greatest impact on tissue deposition rates. The model was also highly sensitive to changes in the maximum velocity and steepness parameter of the lysine utilisation for muscle protein synthesis. The model was further tested by independent published results. The model successfully predicted the response of pigs to a wide range of variation in nutrient composition. Consequently, the model can be applied to develop feeding strategies to optimise pig production. It also enables prediction of the slaughter performance and the meat quality.
\end{abstract}

Evaluation: Anatomical body composition: Chemical body composition: Pig model

A dynamic mechanistic model for growing and fattening pigs has been described in a companion paper (Halas et al. 2004). The aim of the model was to predict the rate of protein and fat deposition (chemical composition), rate of tissue deposition (anatomical composition) and performance of gilts of $20-105 \mathrm{~kg}$ live weight depending on nutrient intake. Model evaluation is concerned with establishing the appropriateness and accuracy of predictions over a wide range of simulated conditions. The wider the circumstances under which the model predictions are accurate, the more confidence is developed in the appropriateness of the concepts and accuracy of parameters upon which it is based and the more useful will its predictions be (Black, 1995).

The objective of the present paper is to evaluate the response of the pig, as predicted by the growth model, to changes in model parameters and in nutrient intakes. First, the sensitivity of predictions to changes in the main model parameters is evaluated. Second, a comparison of the model predictions with observations from independent published trials is presented.

\section{Sensitivity analysis}

A reference simulation was chosen as a starting point for the sensitivity analyses. The initial live weight was $20 \mathrm{~kg}$ and the simulation was performed for $30 \mathrm{~d}$. The pig response to a normal diet (digestible energy $15 \cdot 1 \mathrm{MJ} / \mathrm{kg}$, ileal digestible lysine $11.2 \mathrm{~g} / \mathrm{kg}$, ileal digestible amino acids $157.8 \mathrm{~g} / \mathrm{kg}$, digestible fat $53 \mathrm{~g} / \mathrm{kg}$, starch $404 \mathrm{~g} / \mathrm{kg}$, sugar $25 \mathrm{~g} / \mathrm{kg}$, fermentable cell wall components $67 \mathrm{~g} / \mathrm{kg}$ ) was predicted. The animals were fed at $3.2 \times$ maintenance energy requirements.

\section{Sensitivity to changes in maintenance protein and maintenance energy requirements}

As discussed in the companion paper, maintenance protein and energy requirements are accounted for (Halas et al. 2004). Obligatory $\mathrm{N}$ losses in urine and endogenous gut protein losses are considered implicitly in the model. The daily integument loss was assumed to be $0.094 \mathrm{~g}$ protein/ $\mathrm{kg}$ metabolic body weight $\left(\mathrm{kg}^{0.75}\right)$. Multiplying the default value of skin and hair loss by 0.4 or 2.0 gave a small change in protein and fat deposition rates and average body gain. Although these changes are negligible, the model predictions are reasonable. An increased value of integument loss increases the utilisation of lysine and other amino acids to hide protein synthesis. A larger drain to protein synthesis reduces the lysine concentration and hence reduces the utilisation of lysine and other

\footnotetext{
Abbreviations: FDR, fractional degradation rate; MSPE, mean square prediction error.

* Corresponding author: Dr Veronika Halas, fax +36 82313 562, email halas@mail.atk.u-kaposvar.hu
} 
amino acids for body protein synthesis or for oxidation to acetyl-CoA.

The maintenance energy requirements are considered to be related to carcass protein mass, organ protein mass and body fat mass (Halas et al. 2004). In the reference simulation, the maintenance energy requirements corresponded to $443 \mathrm{~kJ} / \mathrm{kg}^{0 \cdot 75}$ per d. Maintenance energy requirements were varied between 0.7 and $1.6 \times$ default value, and results are presented in Fig. 1. As expected, increasing maintenance energy requirements by $50 \%$ decreases deposition rates of protein, fat and body gain by 7, 28 and $11 \%$ respectively. Maintenance energy in the model is provided by ATP-yielding transactions and by acetyl-CoA oxidation. Increasing the maintenance energy expenditure increases acetyl-CoA oxidation and lowers its concentration. Subsequently, protein synthesis and de novo fat synthesis are reduced, resulting in lower deposition rates of protein and fat.

\section{Sensitivity to changes in fractional degradation rates}

The accretion rate of muscle protein determines the organ, hide and bone protein accretion rates (Halas et al. 2003). Deposition is defined as the difference between synthesis and degradation, where fractional degradation rates (FDR) are assumed constant for each tissue. By changing the FDR of protein pools, protein turnover can be manipulated. As discussed by Gerrits et al. (1997), who used a similar approach, testing the sensitivity of model predictions to changes in the FDR of muscle protein is complicated by the relationships between muscle protein deposition and protein deposition in organs, bone and hide. Therefore, the results of testing model responses to changes in the FDR of muscle protein are similar to those of Gerrits et al. (1997). An increase in the FDR of muscle protein from $0 \cdot 010$ to $0 \cdot 030 /$ d (default $0 \cdot 0223 / \mathrm{d}$ ) decreases body protein deposition rate and average daily gain from 199 to $100 \mathrm{~g} / \mathrm{d}$ and from 1056 to $626 \mathrm{~g} / \mathrm{d}$ respectively. The body fat deposition rate decreases slightly from 162 to $159 \mathrm{~g} / \mathrm{d}$. It can be concluded that the parameters are

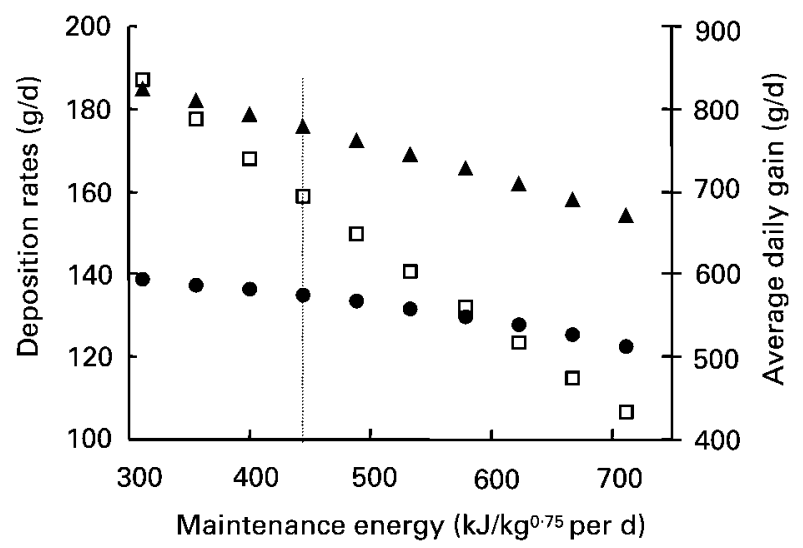

Fig. 1. Sensitivity of predicted average daily gain $(g / d, \Delta)$, protein deposition rate $(\mathrm{g} / \mathrm{d}, \boldsymbol{\bullet})$ and fat deposition rate $(\mathrm{g} / \mathrm{d}, \square)$ to changes in maintenance energy requirement. :, Default value. For details of the model and procedures, see Halas et al. (2004) and p. 726. interrelated. Changes in the FDR of muscle protein are logically accompanied by changes in transactions related to total body protein rather than only muscle protein metabolism.

Model responses to changes in the FDR of organ, hide and bone protein and body fat are given in Fig. 2. Generally, the rate of body protein deposition is hardly influenced by the FDR of organ, hide and bone protein, because the deposition rates of these protein pools are related to the rate of muscle protein deposition (Halas et al. 2004). In contrast, fat deposition rates decrease, because of an increased energy expenditure from protein turnover. Increasing the FDR of organ protein from 0.178 to $0 \cdot 356 / \mathrm{d}$ reduces the protein and fat deposition rates by 0.7 and $5.5 \%$ respectively. Due to the decreasing protein and fat deposition rates, average daily gain also decreases with increasing FDR (Fig. 2). The minor change in body protein deposition is caused by the slight change in amino acid oxidation with changing FDR, as discussed by Gerrits et al. (1997). Increasing the FDR of hide protein from 0.020 to $0.040 / \mathrm{d}$ decreases protein and fat deposition rates by 0.2 and $1.2 \%$ respectively. Increasing the FDR of bone protein from 0.050 to $0 \cdot 100 / \mathrm{d}$ decreases protein and fat deposition rates by 0.2 and $1.1 \%$ respectively. Model sensitivity to changes in the FDR of body fat was examined in the range $0 \cdot 000-0 \cdot 040 / \mathrm{d}$ (default $0 \cdot 010 / \mathrm{d}$ ). Protein deposition rate increased from 135 to $137 \mathrm{~g} / \mathrm{d}$ and fat deposition rate decreased from 161 to $151 \mathrm{~g} / \mathrm{d}$ (Fig. 2). Unlike the results obtained in a veal calf model of Gerrits et al. (1997), changing the FDR of body fat only has a small impact on the acetyl-CoA concentration via the fatty acid pathway and results in a slightly changed protein and fat synthesis. In the measured period (20-46 kg body weight), the fat content of the body is small compared with a larger body weight. Increasing the FDR of the fat pool would not yield much extra fatty acid. On the other hand, the increased fatty acid concentration also increases the body fat synthesis. Hence, a large effect of a change in the FDR of body fat was not expected.

\section{Sensitivity to changes in kinetic parameters}

The sensitivity of the model predictions to changes in kinetic parameters of protein and energy metabolism is given in Table 1. Default model values of all kinetic parameters (maximum velocity Vij, affinity constants Mijk, inhibition constants Jkjk, steepness parameters $\mathrm{Sij}$ ) were used in the reference simulation and changed by -20 and $+20 \%$. The response of the flux as well as effects on body protein and fat deposition rates and the average daily gain were examined.

Changing the maximum velocity of lysine utilisation to muscle protein (Vlymp) has the largest influence on protein deposition (Table 1). A reduced maximum velocity of muscle protein synthesis rate obviously decreases the protein and increases the fat deposition rate. According to the decreased protein synthesis, more lysine and other amino acids are oxidised and yield acetyl-CoA for de novo fatty acid and body fat synthesis. The average daily gain was expected to reflect the protein deposition rate to a large 

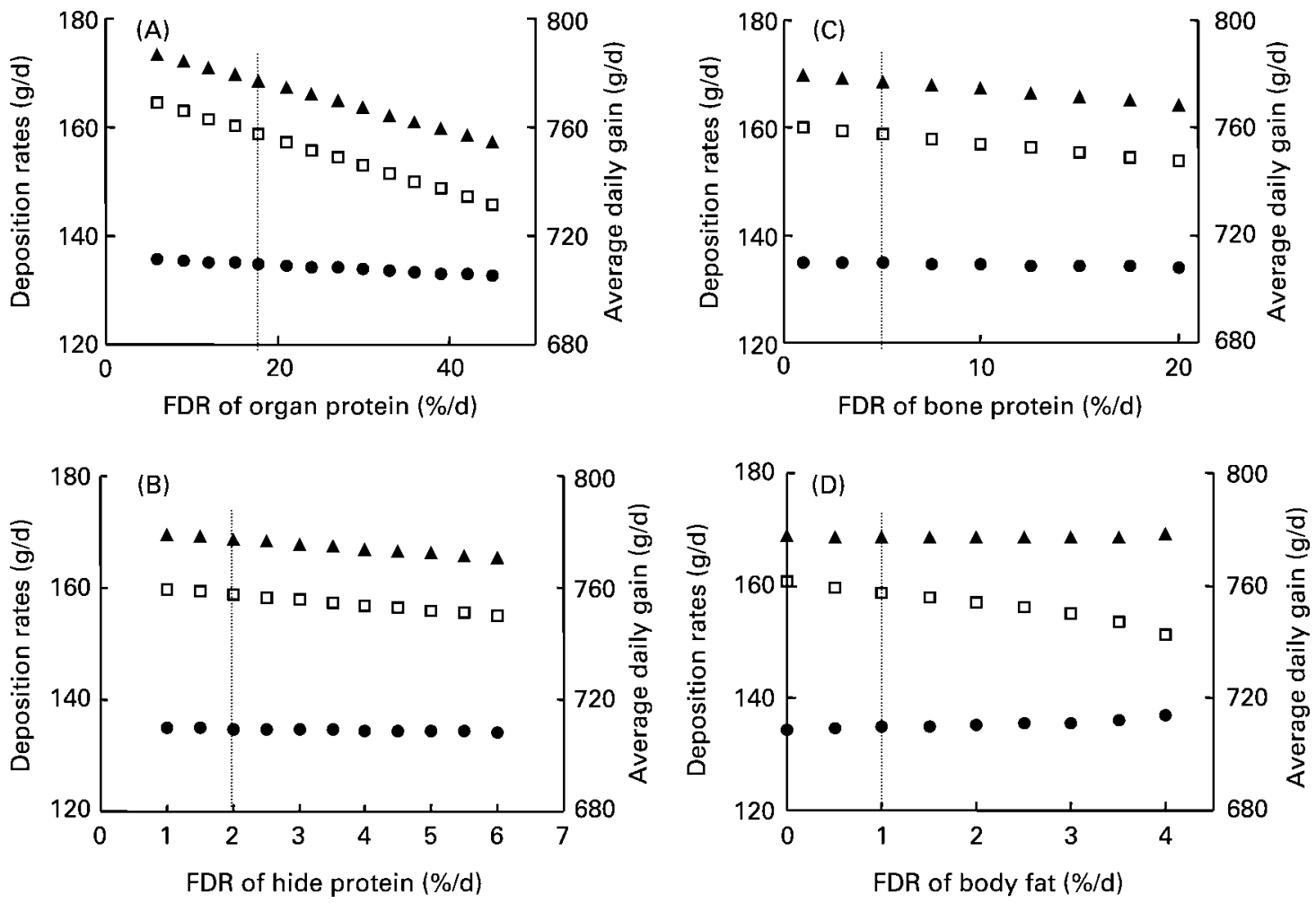

Fig. 2. Sensitivity of predicted average daily gain $(\mathrm{g} / \mathrm{d}, \mathbf{\Delta})$, protein deposition rate $(\mathrm{g} / \mathrm{d}, \bullet)$ and fat deposition rate $(\mathrm{g} / \mathrm{d}$, $\square)$ to changes in fractional degradation rates (FDR) of the organ protein pool (A), hide protein pool (B), bone protein pool (C) and body fat pool (D). :, Default value. For details of the model and procedures, see Halas et al. (2004) and p. 726.

extent, since protein gain is accompanied by deposition of water and minerals. A $20 \%$ increase in Vlymp increases the simulated protein synthesis and slightly decreases the simulated fat synthesis. Therefore, a higher body weight at day 30 of simulation was obtained compared with the reference situation. The nutrient intake increased proportionally with metabolic body weight. Hence, at higher body weight the pig received more feed per d, leading to an increased rate of fat deposition. This completely compensates the reduced energy available for fatty acid

Table 1. Sensitivity of predicted body protein and fat deposition, average daily gain and the size of the transaction to changes in kinetic parameters*

\begin{tabular}{|c|c|c|c|c|c|c|c|c|}
\hline & \multicolumn{2}{|c|}{$\begin{array}{l}\text { Change in protein } \\
\text { deposition }(\mathrm{g} / \mathrm{d})\end{array}$} & \multicolumn{2}{|c|}{$\begin{array}{l}\text { Change in fat } \\
\text { deposition }(g / d)\end{array}$} & \multicolumn{2}{|c|}{$\begin{array}{l}\text { Change in average } \\
\text { daily gain }(\mathrm{g} / \mathrm{d})\end{array}$} & \multicolumn{2}{|c|}{$\begin{array}{l}\text { Effect on the flux } \\
\qquad(\mathrm{mmol} / \mathrm{d})\end{array}$} \\
\hline & $-20 \%$ & $20 \%$ & $-20 \%$ & $20 \%$ & $-20 \%$ & $20 \%$ & $-20 \%$ & $20 \%$ \\
\hline Vlymp & -48.9 & $46 \cdot 7$ & $1 \cdot 1$ & 0.3 & -211 & 200 & $-29 \cdot 5$ & $30 \cdot 4$ \\
\hline Mly,lymp & 5.8 & $-5 \cdot 6$ & 0.0 & 0.1 & 25 & -24 & 3.5 & $-3 \cdot 4$ \\
\hline May,lymp & 2.9 & $-2 \cdot 6$ & -0.1 & 0.1 & 11 & -11 & 1.9 & -1.8 \\
\hline Slymp & $-11 \cdot 0$ & $7 \cdot 8$ & 0.2 & -0.1 & -47 & 34 & -6.7 & $4 \cdot 8$ \\
\hline Mly,lyay & $-6 \cdot 3$ & $4 \cdot 2$ & 4.9 & $-3 \cdot 7$ & -22 & 14 & 2.7 & -1.8 \\
\hline Slyay & $-7 \cdot 6$ & $4 \cdot 3$ & $5 \cdot 8$ & $-3 \cdot 8$ & -27 & 15 & 3.0 & -1.8 \\
\hline Vayfa & 3.5 & $-3 \cdot 3$ & $-4 \cdot 3$ & 3.6 & 11 & -11 & $-404 \cdot 6$ & $333 \cdot 1$ \\
\hline May,ayfa & $-2 \cdot 0$ & 1.5 & $2 \cdot 2$ & -1.8 & -6 & 5 & $226 \cdot 4$ & $-178 \cdot 3$ \\
\hline Jfa,ayfa & 0.0 & 0.0 & 0.0 & 0.0 & 0 & 0 & -1.7 & $1 \cdot 2$ \\
\hline Vaygr & 1.4 & -1.5 & $9 \cdot 7$ & $-9 \cdot 0$ & 16 & -16 & $-536 \cdot 0$ & $493 \cdot 6$ \\
\hline May,aygr & -0.5 & 0.4 & $-3 \cdot 3$ & 2.9 & -6 & 5 & $217 \cdot 7$ & $-185 \cdot 0$ \\
\hline Mly,aygr & -0.7 & 0.6 & -4.4 & 3.9 & -8 & 7 & $216 \cdot 2$ & $-194 \cdot 8$ \\
\hline Mfa,faay & 0.2 & -0.2 & -0.4 & 0.4 & 0 & 0 & 6.7 & $-6 \cdot 1$ \\
\hline Jay,faay & -0.5 & 0.4 & $1 \cdot 3$ & $-1 \cdot 1$ & -1 & 1 & -12.5 & $10 \cdot 5$ \\
\hline Vfatf & 0.5 & -0.4 & -1.5 & 1.0 & 1 & -1 & $-7 \cdot 2$ & $5 \cdot 9$ \\
\hline Mfa,fatf & -0.2 & 0.2 & 0.6 & -0.4 & 0 & 0 & 3.9 & -2.9 \\
\hline
\end{tabular}

$\mathrm{V}$, maximum velocity of the transaction; M, affinity constant; J, inhibition constant; S, steepness parameter; ly, lysine; mp, muscle protein; ay, acetyl-CoA; fa, fatty acid; gr, extra energy for growth; tf, total body fat.

* For details of the model and procedures, see Halas et al. (2004) and p. 726 
synthesis as a result of increased energy expenditure on protein deposition. Consequently, both the body protein and body fat deposition rate increases with increasing Vlymp due to a higher intake at higher body weight (Table 1).

Increasing the affinity constants for lysine or acetyl-CoA use in muscle protein synthesis (Mly,lymp and May,lymp) reduces protein synthesis and thereby protein deposition (Table 1). Changing the steepness parameter (Slymp) changes the steepness of the saturation curve. However, the effect of changing a steepness parameter generally depends on metabolite concentrations. Considering the rate of the flux is about half of its maximum (with substrate concentration close to the value of the affinity constant), the transaction is sensitive to changes in $\mathrm{Sij}$. Changing Slymp by $\pm 20 \%$ results in -11.0 and $+7.8 \mathrm{~g} / \mathrm{d}$ change in the rate of protein deposition. The affinity constants and the steepness parameter related to protein synthesis slightly influence the fat deposition as well.

As expected, the rate of lysine oxidation (Uly,lyay) is increased by either a higher maximum velocity, a lower affinity constant or a lower steepness parameter (Table 1). Increasing oxidation reduces protein synthesis and daily protein deposition and increases acetyl-CoA concentration. It thereby increases de novo fatty acid synthesis and results in an increased rate of fat deposition.

Generally, changing the maximum velocity of the reaction has the largest impact on the flux and on predicted protein and fat deposition rates (Table 1). Increasing Vij values of the fatty acid or the fat synthesis decreases the protein deposition rate slightly, while the increase of fat deposition rates are more pronounced. By increasing Vayfa, the acetyl-CoA pool decreases due to the larger drain on the fatty acid pool. The resulting increase in fatty acid pool size increases the synthesis rate of body fat, while the lower acetyl-CoA concentration slightly reduces the rate of protein synthesis. Increasing Vfatf increases the rate of body fat synthesis and reduces the fatty acid pool size. Consequently, the rate of fatty acid oxidation is reduced as well as the acetyl-CoA pool size, which, in turn, reduces the rate of protein synthesis. Changing kinetic parameters of fatty acid oxidation generally results in effects opposite to those resulting from changing kinetic parameters of fatty acid synthesis. Increasing Vfaay results in slightly higher protein and lower fat deposition rates.

In general, the mechanisms discussed earlier in protein or in energy metabolism result in opposite changes of protein and fat deposition rates. An exception to this general observation is the response to a change in 'additional energy for growth'. Increasing the maximum velocity of this transaction (Vaygr) reduces both the protein and fat deposition rates by reducing acetyl-CoA pool size and subsequently acetyl-CoA concentration (Table 1).

Results of changes in Mijk values are in the opposite direction to those of changes in Vij, because a higher affinity constant reduces the particular flux rate (Table 1). The flux of fatty acid oxidation is regulated by affinity and inhibition constants (Mfa,faay and Jay,faay). The purpose of the inhibition constant is to prevent acetyl-CoA accumulating in the model. In changing Jay,faay by $\pm 20 \%$, the change in deposition rate is $-0.5 v .0 .4 \mathrm{~g} / \mathrm{d}$ and that in the fat deposition rate is $1.3 v$. $-1.1 \mathrm{~g} / \mathrm{d}$. The effect of the inhibition constant in fatty acid synthesis is negligible. Changing kinetic parameters involved in glucose and volatile fatty acid metabolism only marginally affect fluxes of related metabolites. This is expected, as these parameters were set to prevent accumulation of these metabolites. Therefore, results of these sensitivity analyses are not presented.

\section{Sensitivity to changes in energy requirements for tissue deposition}

The effect of changing some of the main stoichiometric assumptions was tested using the reference simulation as a starting point. The energy costs of protein synthesis, protein degradation, fat synthesis and $\mathrm{Ca}$ and $\mathrm{P}$ incorporation in bone were varied. Table 2 presents the changes in predicted deposition rates and heat production compared with the reference simulation. Increasing the ATP requirement for peptide bond formation (default is 4 ATP per peptide bond) or hydrolysis (default is 1 ATP per peptide bond cleavage) decreases protein and fat deposition rates and hence the average daily gain. Total heat production increases with increasing energy cost of the protein turnover. The ATP requirement for fat synthesis is $4 \mathrm{~mol}$ ATP for glycerol phosphate production and 2 mol ATP for fatty acid activation. An increase in the default energy cost of fat synthesis and bone mineralisation (default is 2 ATP per mol Ca and P incorporation) hardly changes the heat production (Table 2). In general, increasing the energy cost of the intermediary transactions will increase the drain of acetyl-CoA oxidation and the model responses are similar to increasing 'additional energy cost for growth'.

It has been suggested that the energy content of ATP is different depending on the metabolite (i.e. glucose, tripalmitin, amino acids) from which it was generated (van Milgen, 2002). Thus, due to the uncoupling of ATP synthesis in the mitochondrion, $1 \mathrm{~mol}$ acetyl-CoA may give less ATP than assumed previously. Considering that assumption in the context of the model, the reduction of ATP production potential of acetyl-CoA results in a reduced production of acetyl-CoA equivalents, since the transactions in which ATP are produced supply less acetyl-CoA. A decrease in acetyl-CoA concentration, such as in cases of increasing maintenance energy requirement and 'additional energy for growth', the fat synthesis decreases with a slight reduction in protein synthesis as well.

\section{Conclusion of the sensitivity analyses}

In conclusion, the growth model for fattening pigs is sensitive to changes in a number of the examined model parameters. Changes in the maintenance energy requirements and the FDR of muscle protein have the greatest impact on tissue deposition rates. The model is highly sensitive to changes in the maximum velocity and steepness parameter of the lysine utilisation for muscle protein synthesis. Those parameters directly affecting the size of the lysine pool generally have a considerable influence 
Table 2. The effect of changing stoichiometric assumptions in the model simulating metabolism of growing pigs on the energy costs of protein synthesis, protein degradation, fat synthesis and mineralisation*

\begin{tabular}{|c|c|c|c|c|c|}
\hline & & $\begin{array}{l}\text { Change in protein } \\
\text { deposition }(\mathrm{g} / \mathrm{d})\end{array}$ & $\begin{array}{l}\text { Change in fat } \\
\text { deposition }(g / d)\end{array}$ & $\begin{array}{l}\text { Change in average } \\
\text { daily gain }(\mathrm{g} / \mathrm{d})\end{array}$ & $\begin{array}{l}\text { Change in heat } \\
\text { production (\%) }\end{array}$ \\
\hline \multirow[t]{2}{*}{ Protein synthesis } & 4 ATP† & & & & \\
\hline & 5 ATP & $\begin{array}{r}0.7 \\
-0.7\end{array}$ & $\begin{array}{r}4.4 \\
-4.4\end{array}$ & $\begin{array}{r}7.5 \\
-7.6\end{array}$ & $\begin{array}{r}-1.7 \\
1.6\end{array}$ \\
\hline \multirow[t]{3}{*}{ Protein degradation } & 1 ATP† & & & & \\
\hline & 0 ATP & 0.4 & 2.9 & 4.9 & $-1 \cdot 2$ \\
\hline & 2 ATP & -0.5 & -2.9 & -4.9 & 1.2 \\
\hline \multirow[t]{3}{*}{ Fat synthesis } & 6 ATP† & & & & \\
\hline & 3 ATP & 0.3 & 1.7 & 2.9 & -0.7 \\
\hline & 9 ATP & -0.3 & -1.6 & $-2 \cdot 8$ & 0.7 \\
\hline \multirow[t]{3}{*}{ Mineralisation } & 2 ATP† & & & & \\
\hline & 0 ATP & 0.2 & $1 \cdot 1$ & 1.9 & -0.4 \\
\hline & 4 ATP & -0.2 & $-1 \cdot 1$ & -1.9 & 0.4 \\
\hline
\end{tabular}

${ }^{*}$ For details of the model and procedures, see Halas et al. (2004) and p. 726

† Reference values.

on the model predictions. Furthermore, it should be noted that the results of this sensitivity analysis depend on the nutrient intakes of the reference simulation. The reason for the relative insensitivity of the model to the changes of parameters related to energy metabolism is probably that protein and/or lysine is more limiting within the simulated circumstances.

\section{Comparison of model predictions with published trials}

Independent data sets of published experiments were used to evaluate model performance. The literature studies were selected based on the following principles: (1) representing a large variation of nutrient intakes; (2) a high genetic potential population was used in the trial; (3) the chemical composition of the body was determined by comparative slaughter techniques. The digestible nutrient compositions of the diets were recalculated based on a Dutch table of values (Central Veevoeder Bureau, 1998). Data from different studies were simulated and the model predictions were compared with experimental observations. As an indicator for the error of predicted values relative to the observed values, the mean square prediction error (MSPE) was calculated:

$$
\mathrm{MSPE}=\Sigma(\mathrm{Oi}-\mathrm{Pi})^{2} / n,
$$

where $\mathrm{Oi}$ and $\mathrm{Pi}$ are the observed and predicted values; $\mathrm{i}=1, \ldots, n ; n$ is number of experimental observations (Bibby \& Toutenburg, 1977). The root MSPE is a measure in the same units as the output and is expressed as a percentage of the observed mean. The MSPE may be deconstructed into three fractions. First, errors attributed to overall bias (B \%) represent the proportion of MSPE due to a consistent over- or underestimation of the experimental observations by the model predictions. Second, deviation of regression slope from 1, being the line of perfect agreement $(\mathrm{R} \%)$ represents the proportion of MSPE due to inadequate simulation of differences between experimental observations. Third, disturbance proportion (E\%) represents the proportion of MSPE unrelated to the errors of model prediction. The prediction is very good if the
MSPE is small and if a small proportion of MSPE is explained by the regression error and the deviance in bias.

\section{Model response to variation in dietary protein content}

Chen et al. (1999) evaluated the effect of increasing protein intake on growth performance and carcass characteristics of finishing gilts. The animals received one of five dietary treatments: $130,160,190,220$ and $250 \mathrm{~g}$ crude protein $(\mathrm{N} \times 6 \cdot 25) / \mathrm{kg}$ diet (five per group). Pigs were allowed ad libitum access to the diets, which were formulated to be equal in metabolisable energy content $(13.74 \mathrm{MJ} / \mathrm{kg})$, and dietary protein was exchanged for starch. Initial body weight was $51 \mathrm{~kg}$ and the trial was conducted on time constant basis of $75 \mathrm{~d}$. The observed nutrient intakes were considered in the simulation.

The predictions of average daily gain, the carcass gain and carcass protein and fat deposition rates are shown in Fig. 3. The MSPE and the decomposition of MSPE are presented in Table 3 . The root MSPE of average daily gain, carcass weight gain, carcass protein and fat deposition rates varied between 39 and $71 \%$ of the observed mean value (Table 3). For average daily gain, carcass weight gain and carcass protein gain, most $(>90 \%)$ of this error was attributed to an overall bias, and these gains were over-predicted by 356, 405 and $72 \mathrm{~g} / \mathrm{d}$ respectively. For carcass fat deposition, a higher proportion of MSPE was attributed to deviation in slope, and less to overall bias ( $\mathrm{R} \% 29, \mathrm{~B} \%$ 68) compared with the other parameters.

Experimental variations in average daily gain, carcass weight gain and carcass protein gain were well predicted by the model. The consistent overestimation can be caused by erroneous model predictions, or alternatively reflects a real difference in experimental conditions between Chen et al. (1999) and our calibration datasets (Bikker et al. 1994, 1995, 1996a,b). At ad libitum feed intake the pigs gained on average $1307 \mathrm{~g} / \mathrm{d}$ between 45 and $85 \mathrm{~kg}$ body weight in the trial of Bikker et al. $(1996 b)$. However, the average daily gain was only $817-$ $926 \mathrm{~g} / \mathrm{d}$ in the $51-110 \mathrm{~kg}$ weight range in the trial of Chen et al. (1999). Experimental variation in the rate of carcass fat deposition was less well predicted. This is 
(A)

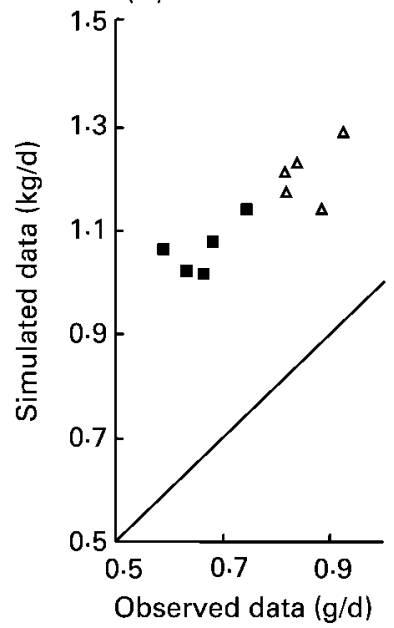

(B)

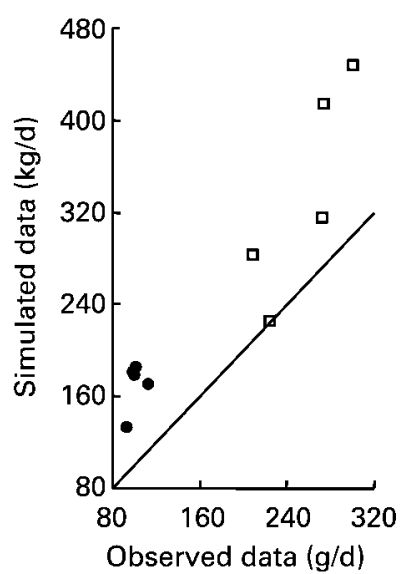

Fig. 3. Comparison of experimental observations with model of average daily gain $(\mathrm{kg} / \mathrm{d}, \mathbf{\square})$ and carcass gain $(\mathrm{kg} / \mathrm{d}, \Delta)((\mathrm{A}), x=y)$, and carcass protein deposition rate $(\mathrm{g} / \mathrm{d}, 0)$ and carcass fat deposition rates $(\mathrm{g} / \mathrm{d}, \square)((\mathrm{B}), x=y)$ in the experiment of Chen et al. (1991). For details of the model and procedures, see Halas et al. (2004) and p. 729. For the mean square prediction error analysis performed for each parameter, see Table 3.

likely to be related to the low variation in the carcass fat deposition rate $(85 \mathrm{~g} / \mathrm{d})$ between the experimental treatments of Chen et al. (1999). Considering that the experimental contrast was $130 v$ v. $250 \mathrm{~g}$ crude protein $(\mathrm{N} \times 6.25) / \mathrm{kg}$ in the diets, one would expect a large variation in fat deposition rate within the trial. Furthermore, it illustrates the complexity of good predictions of fat deposition rates. Generally, fat deposition is considered a depot for nutrients remaining after meeting maintenance requirements and providing nutrients and fuel for protein deposition (Whittemore \& Fawcett, 1976). Therefore, any difference in experimental conditions between the experiment of Chen et al. (1999) and our present calibration datasets would be expected to be reflected first in differences in fat deposition rates. The model over-predicted the fat and protein deposition rates. The pigs in the trial of Bikker et al. (1996b) were more efficient than those in the trial of Chen et al. (1999). The energetic efficiency of energy retention in the carcass from daily metabolisable energy intake was on average $44.4 \%$ in the trial of Bikker et al.

(1996b) and in a range of $26.6-31.9 \%$ in the trial of Chen et al. (1999).

\section{Model response to variation in dietary lysine and protein level}

Noblet et al. (1987) studied the effect of a reduction in protein level with or without lysine supplementation on energy and $\mathrm{N}$ balance. Thirty-two female Large White pigs with an initial body weight of $20 \mathrm{~kg}$ were used in the experiment. The pigs were assigned to three treatment groups (eight animals per treatment) and fed for 7 weeks. The dietary crude protein $(\mathrm{N} \times 6.25)$ and lysine contents of the diets were 153.0 and $6.7 \mathrm{~g} / \mathrm{kg}$ (diet 1 ), 153.0 and $8.0 \mathrm{~g} / \mathrm{kg}$ (diet 2) or 178.0 and $8.1 \mathrm{~g} / \mathrm{kg}$ (diet 3) respectively. The diets were based on maize and soyabean meal. The composition of diets 1 and 2 were similar, except that diet 2 was supplemented with lysine. A small proportion of maize was replaced by soyabean meal in diet 3 . Diets were isoenergetic on a gross energy basis and the pigs received $120 \mathrm{~g} \mathrm{diet} / \mathrm{kg}^{0.75}$ per d. A digestibility study was also performed to define the digestible protein, lysine and energy contents of the diets. The digestible energy contents of the diets were $14.2,14.2$ and $14.4 \mathrm{MJ} / \mathrm{kg}$ for diets 1,2 and 3 respectively on an as-fed basis. The higher digestible energy content of diet 3 was caused by the higher protein content and its associated higher digestibility. At the end of the fattening trial (at about $53 \mathrm{~kg}$ body weight) the pigs were slaughtered. The bodies were dissected and the chemical composition was measured in different fractions.

The experimental observations and the model predictions and the prediction errors are presented in Table 4. The average daily gain, the empty body gain and the carcass gain are overestimated. The prediction errors are due to the overall bias in all cases (B \% 99). However, the predicted increase in gain following an increase in lysine content (diet $1 v$. diet 2) was qualitatively in line with observed values, and similarly both observations and predictions indicate the absence of an effect of increasing protein content (diet $2 v$. diet 3) on gain. Although the muscle gain is underestimated by on average $17 \mathrm{~g} / \mathrm{d}$, the relative MSPE is only $5 \%$ of the observed mean value. In contrast, the organ and adipose tissue gains are overestimated by 13 and $11 \mathrm{~g} / \mathrm{d}$ respectively, with a relative MSPE of 15 and $9 \%$ of the

Table 3. Mean square prediction error (MSPE) and decomposition of the MSPE*

\begin{tabular}{|c|c|c|c|c|c|}
\hline & rootMPSE & reIMPSE \% & $\mathrm{B} \%$ & $\mathrm{R} \%$ & $E \%$ \\
\hline \multicolumn{6}{|l|}{ Chen et al. (1999) } \\
\hline Average daily gain $(\mathrm{kg} / \mathrm{d})$ & 0.356 & $41 \cdot 6$ & $98 \cdot 0$ & 0.8 & $1 \cdot 2$ \\
\hline Carcass weight gain $(\mathrm{kg} / \mathrm{d})$ & 0.405 & $61 \cdot 1$ & $99 \cdot 1$ & 0.1 & 0.8 \\
\hline Carcass protein deposition $(\mathrm{g} / \mathrm{d})$ & $71 \cdot 7$ & $71 \cdot 1$ & 94.4 & $5 \cdot 0$ & 0.6 \\
\hline Carcass fat deposition $(\mathrm{g} / \mathrm{d})$ & 99.4 & 38.9 & $68 \cdot 3$ & 28.5 & $3 \cdot 2$ \\
\hline \multicolumn{6}{|l|}{ Van Lunen \& Cole (1996) } \\
\hline Average daily gain $(\mathrm{kg} / \mathrm{d})$ & 0.086 & $9 \cdot 7$ & $17 \cdot 9$ & $6 \cdot 9$ & $75 \cdot 2$ \\
\hline Feed conversion ratio $(\mathrm{kg} / \mathrm{kg})$ & 0.219 & $10 \cdot 3$ & $10 \cdot 7$ & $2 \cdot 3$ & $87 \cdot 0$ \\
\hline Protein deposition $(\mathrm{g} / \mathrm{d})$ & $16 \cdot 2$ & $11 \cdot 3$ & $2 \cdot 7$ & $1 \cdot 7$ & $95 \cdot 6$ \\
\hline Fat deposition $(\mathrm{g} / \mathrm{d})$ & $22 \cdot 6$ & $12 \cdot 6$ & 0.5 & $22 \cdot 6$ & 76.9 \\
\hline
\end{tabular}

rootMPSE, root MSPE; relMSPE \%, root MSPE expressed as a percentage of the observed mean; $\mathrm{B} \%$, error attributed to overall bias of prediction; $\mathrm{R} \%$, error attributed to the deviation of the regression slope from $1 ; \mathrm{E} \%$, error due to the data disturbance.

*From Chen et al. (1991) and Van Lunen \& Cole (1996). 
observed mean respectively. Again, the overall bias proportion was the major contributor to the MSPE, whilst the deviation of regression slope from one had a minor contribution to the MSPE. The model predicts the muscle protein deposition correctly. The $5 \%$ relative MSPE is primarily caused by the $5 \mathrm{~g} / \mathrm{d}$ overestimation with diet 1 . Carcass protein, body protein and body fat deposition rates are overestimated by 30,25 and $17 \mathrm{~g} / \mathrm{d}$ respectively. More than $90 \%$ of the MSPE was attributed to the overall bias. As before, the predictions were qualitatively in line with observations. The distribution of protein and fat in the empty body and the carcass are predicted satisfactorily, with root MSPE values being $\leq 10 \%$ of the observed mean value. The differences between observations and predictions are $1.6,1.0,1.3$ and $2.7 \%$ for percentage protein and fat deposition in empty body gain, and percentage protein and fat deposition in carcass gain respectively. The overall bias contributed most to the MSPE.

The daily muscle protein deposition rate is slightly overestimated (root MSPE expressed as a percentage of the observed mean value is 5), while the predicted daily protein deposition rates in carcass and body are 37 and $25 \%$ greater than observed in the trial. This suggests that the protein deposition rates in non-muscle fractions are overpredicted, especially in bone and hide. This in turn will give rise to a much higher carcass weight and carcass gain at the end of the simulation than observed in the experiment. Alternatively, the dissection method could cause a difference in anatomical composition between observation and prediction.

Overall, the qualitative behaviour of the model was very much in accordance with observations. In particular, the muscle and adipose tissue gain, and muscle protein deposition and body fat deposition, and the percentage of protein and fat deposition in gains, were predicted accurately (root MSPE $\leq 10 \%$ of observed mean value). In general, the overall bias was the most significant contributor to the MSPE. Regarding muscle protein deposition, the $\mathrm{R} \%$ is quite high, but the prediction error is small.

\section{Model response to variation in lysine:digestible energy ratio}

Van Lunen \& Cole (1996) examined the effects of the dietary lysine:digestible energy ratio on growth performance and body composition of boars, gilts and barrows from 25 to $90 \mathrm{~kg}$ live weight. Twelve pigs (four of each gender) were assigned to each dietary treatment consisting of lysine:digestible energy ratios from 0.4 to 1.4 , in $0.2 \mathrm{~g} / \mathrm{MJ}$ increments. Feed was provided at about 09.00 hours ad libitum. The chemical body composition of two pigs per gender per treatment was determined. In the experiment, the feed intake, daily gain, feed conversion and the daily protein gain were not affected by gender. Lipid gain, however, was influenced by gender, and the gilts had a lipid deposition rate in between barrows and boars. The simulations were conducted for a fixed body weight range $(25-90 \mathrm{~kg})$ and the feed intake was adjusted to the observed feed consumption in the experiment.

The general agreement of the observed and predicted average daily gain and feed conversion, and daily protein 
and fat deposition rates, can be seen in Fig. 4. The MSPE and the decomposition of the MSPE are presented in Table 3 . The model predicted the average daily gain and the feed conversion satisfactorily, with a root MSPE of $10 \%$ of the observed mean value; these errors are mainly due to the disturbance, attributing 75.2 and 87.0\% MSPE respectively (Table 3). The overall bias of body protein and fat deposition rates are estimated correctly. In daily protein deposition, $95.6 \%$ of the prediction error of $16.2 \mathrm{~g} / \mathrm{d}$ is attributed to the disturbance proportion and $2.7 \%$ of it to the overall bias (Table 3). For daily fat deposition, the root MSPE is $12.6 \%$ of the observed mean value, and this error is almost completely attributed to the data disturbance $(76.9 \%)$ and to deviation of the regression slope from $1(22.6 \%)$.

The study of Van Lunen \& Cole (1996) was convenient for several reasons. (1) The aim of the trial (to study the effect of increasing lysine:digestible energy ratio on the performance) was in line with the basic approach of
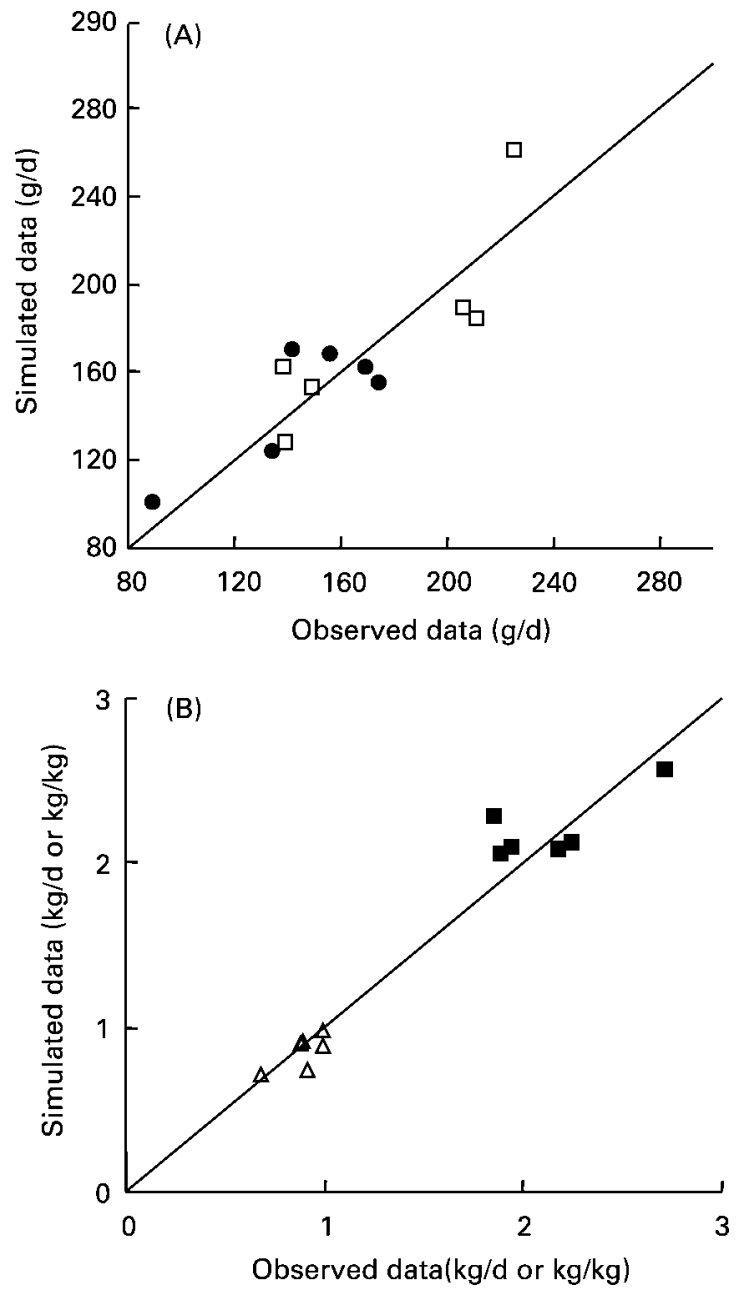

Fig. 4. Comparison of experimental observations with model predictions of average daily gain $(\mathrm{kg} / \mathrm{d}, \triangle)$ and feed conversion ratio $(\mathrm{kg} / \mathrm{kg}, \mathbf{\square})((\mathrm{A}), x=y)$, and carcass protein deposition rate $(\mathrm{g} / \mathrm{d}, \mathbf{0})$ and carcass fat deposition rates $(\mathrm{g} / \mathrm{d}, \square)((\mathrm{B}), x=y)$ in the experiment of Van Lunen \& Cole (1996). For details of the model and procedures, see Halas et al. (2004) and p. 731. For the mean square prediction error analysis performed for each parameter, see Table 3. the model. According to that, lysine is considered the first limiting amino acid in protein synthesis and the energy supply has an impact on protein synthesis. (2) The weight range of the pigs in the trial represented the whole growing and fattening period. (3) The number of dietary treatments and the experimental contrast were sufficient. The model quantitatively predicted the examined parameters with regard to average daily gain, feed conversion ratio, daily body protein and fat deposition. The errors of prediction were substantially explained by the intraexperimental variance within the trial.

\section{Model response to variation in energy sources}

Beech et al. (1991) determined the utilisation of nutrients for energy retention, as affected by the daily fat and starch intake. In that study, three diets were used. Diet 1 was based on wheat and soyabean meal; in diet 2 the wheat was totally replaced by sucrose; diet 3 was formulated using wheat and soyabean oil. The digestible energy and crude protein $(\mathrm{N} \times 6.25)$ content of the diets were $14 \mathrm{MJ} / \mathrm{kg}$ and $207 \mathrm{~g} / \mathrm{kg}$ for diet $1,15 \mathrm{MJ} / \mathrm{kg}$ and $174 \mathrm{~g} / \mathrm{kg}$ for diet 2 , and $15 \mathrm{MJ} / \mathrm{kg}$ and $213 \mathrm{~g} / \mathrm{kg}$ for diet 3 respectively. The diets were fed at $3 \times$ digestible energy maintenance requirement. The trial was carried out with Large White males with an initial body weight of $20 \mathrm{~kg}$. Five pigs were slaughtered at $20 \mathrm{~kg}$ and ten pigs per treatment slaughtered at $50 \mathrm{~kg}$ body weight. Considering that lysine was not the first limiting amino acid in the sucrose diet, the simulations were run for diet 1 (starch) and diet 3 (oil) only. In our simulations, the digestible nutrient content of the diets was recalculated from the Central Veevoeder Bureau (1998) table. The experimental contrast in daily nutrient intakes was $1.82 v .5 .47 \mathrm{~g}$ digestible fat $/ \mathrm{kg}^{0.75}$ and 46.0 v. $38.9 \mathrm{~g}$ digestible carbohydrate $/ \mathrm{kg}^{0.75}$ in diets 1 and 3 respectively.

Experimental observations and model predictions are presented in Table 5. In the present experiment, the decomposition of MSPE is not relevant according to the low number of treatments $(n 2)$. However, the model predictions are generally in line with the observed values. The model predicts the average daily gain and the carcass gain correctly (MSPE $<5.0 \%$ of observed mean value). In both observations and predictions, the energy source affected the fat deposition and the carcass fat content. The model, however, predicts a larger increase in fat deposition and fat content upon exchanging carbohydrate with fat. Observed and predicted fat deposition rate increase 10 and $19 \mathrm{~g} / \mathrm{d}$ respectively. Observed and predicted differences of carcass fat content between pigs fed starch and oil diets are 12 and $23 \mathrm{~g} / \mathrm{kg}$ respectively. The protein deposition and the carcass protein content are overestimated by 18 and $17 \%$. Meanwhile the simulations show slight change between starch and oil treatments in agreement with the observations. The size of prediction errors is within the range of normal inter-experimental variation. The largest difference between observed and predicted values occurred in protein deposition rate and carcass protein content. This was because the real intake of ileal digestible lysine and other amino acids was probably reduced in the experiment, due to a lower digestibility than was 
Table 5. Comparison of experimental observations of Beech et al. (1991) with model predictions of average daily gain, carcass gain, protein and fat deposition rates and carcass protein and fat content ${ }^{\star}$

\begin{tabular}{|c|c|c|c|c|c|}
\hline & \multicolumn{2}{|c|}{ Starch } & \multicolumn{2}{|c|}{ Oil } & \multirow{2}{*}{ RelMSPE \% } \\
\hline & Observed & Predicted & Observed & Predicted & \\
\hline Average daily gain $(\mathrm{g} / \mathrm{d})$ & 668 & 637 & 672 & 638 & 4.9 \\
\hline Carcass gain $(g / d)$ & 528 & 528 & 525 & 527 & $2 \cdot 0$ \\
\hline Protein deposition ( $\mathrm{g} / \mathrm{d})$ & 98 & 117 & 96 & 112 & $18 \cdot 1$ \\
\hline Fat deposition $(\mathrm{g} / \mathrm{d})$ & 109 & 101 & 119 & 122 & $5 \cdot 2$ \\
\hline Carcass protein content $(\mathrm{g} / \mathrm{kg})$ & 157 & 184 & 154 & 179 & $16 \cdot 8$ \\
\hline Carcass fat content $(\mathrm{g} / \mathrm{kg})$ & 180 & 156 & 192 & 179 & $10 \cdot 4$ \\
\hline
\end{tabular}

reIMSPE \%, root mean square prediction error expressed as a percentage of the observed mean value.

${ }^{*}$ For details of the model and procedures, see Halas et al. (2004) and p. 732.

presumed during the simulation. The difference in observed and predicted values can also result from, for example, a different genotype, gender or effect of climatic differences.

In order to study the effect of different energy sources on protein and energy metabolism further, a hypothetical starch-fat exchange was performed. The reference simulation used in sensitivity analysis was chosen as a starting point. The daily fat, starch and digestible energy intakes were $5.4 \mathrm{~g} / \mathrm{kg}^{0.75}, 41.1 \mathrm{~g} / \mathrm{kg}^{0.75}$ and $1.48 \mathrm{MJ} / \mathrm{kg}^{0.75}$ respectively. The fat intake was changed by increments of $1 \mathrm{~g} / \mathrm{kg}^{0.75}$ per $\mathrm{d}$ and the starch intake was adjusted to keep the digestible intake constant. No other nutrient intake was modified; thus, protein intake was the same in each simulation. The simulation was started at $20 \mathrm{~kg}$ body weight and it was run for $58 \mathrm{~d}$. At this point, the cumulative feed intake was very close to $100 \mathrm{~kg}$. The effect of increasing fat intake on average daily gain, protein and fat deposition rates is presented in Fig. 5. As expected, increasing fat intake decreases the daily protein deposition rate and the average body gain, and increases the fat deposition rate. The protein deposition rate decreases from 163 to $140 \mathrm{~g} / \mathrm{d}$ upon an increase in daily fat intake from 1.4 to $9.4 \mathrm{~g} / \mathrm{kg}^{0.75}$ (Fig. 5). In the model, glucose arising from starch is metabolised through the acetyl-CoA pool or is linked directly to fat synthesis in the requirements for glycerol and NADPH, whilst fatty

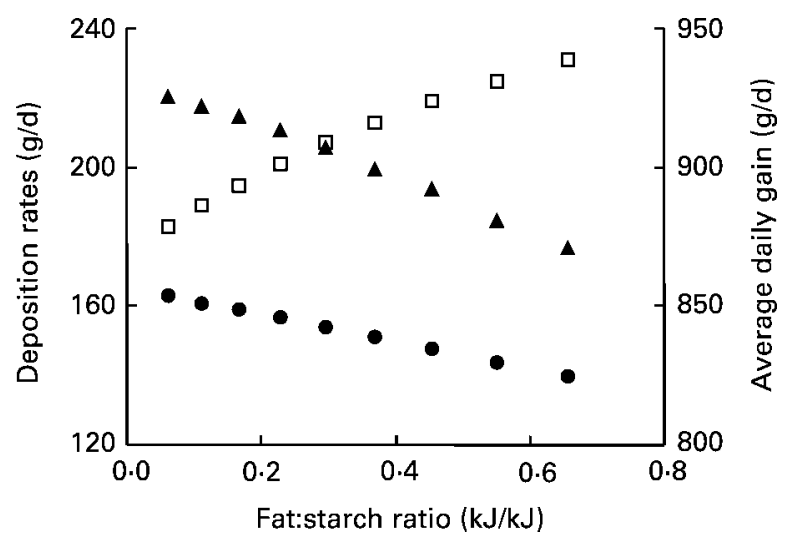

Fig. 5. Effect of variation in the fat:starch ratio on predicted average daily gain $(\mathrm{g} / \mathrm{d}, \boldsymbol{\Delta})$, protein deposition rate $(\mathrm{g} / \mathrm{d}, \bullet)$ and fat deposition rate $(\mathrm{g} / \mathrm{d}, \square)$. For details of the model and procedures, see Halas et al. (2004) and p. 733. acids can be metabolised through acetyl-CoA or directly to body fat. Thus, with increasing dietary fat, the acetyl$\mathrm{CoA}$ concentration probably decreases. Since the protein synthesis is energy dependent, a reduced acetyl-CoA concentration reduces the protein synthesis as well. A decreasing protein synthesis results in a decreasing protein deposition. In the simulations the oxidation of fatty acids hardly changes, even at extreme fat:starch ratios. This is in accordance with the results obtained by indirect calorimetry (Chwalibog et al. 1992, 2001). They found that dietary fat was not oxidised when the energy from carbohydrate was sufficient to cover the energy requirements for growth. Consequently, fatty acids are almost quantitatively deposited. Hence, with a high fat intake, a substantial amount of dietary fat is deposited as body fat. As a result of exchanging starch for fat, the decrease in protein deposition, with associated water deposition, is more pronounced than the increase in fat deposition, giving rise to reduced growth rates. In the pig model of Lizardo et al. (2002) the conversion of dietary fatty acids to body fat was considered to be 0.85 , indicating that some part of dietary fat is used for energy production as well. As they concluded, the literature is not convincing as regards the efficiency of fat utilisation; therefore, more studies are needed for clarification.

The growth model was not calibrated directly to simulate the pig response to different energy sources; however, the model was also evaluated upon exchanging starch for lipids. There are only a few studies presenting the effect of energy source on protein and fat deposition. Some of these studies (Chwalibog et al. 1992, 2001) show a tendency for fat retention to increase upon feeding dietary fat or oil compared with pigs receiving an isoenergetic starch diet. According to indirect calorimetry studies, the mechanism of the energy metabolism seems to be presented reasonably in the model. It has to be noted, however, that more data are needed to quantitatively predict the pig's response to changes in dietary non-protein energy sources.

\section{Conclusion of model testing with independent results}

In general, the model satisfactorily predicts the qualitative pig responses to variations in nutrient supply. The predicted chemical and anatomical body composition and also the distribution of protein and fat were sufficient in 
model testing. In most cases, the errors due to the deviation of the regression slope from 1 were minor. A major factor contributing to the large bias observed for most growth characteristics is the variation in pig performance among genotypes. Adopting the model for different strains can solve that problem (discussed in Halas et al. 2004). Based on the comparison of the model simulations with independent data sets, it is important to improve the model regarding the effect of energy sources on deposition rates.

\section{Implication of the growth model}

The model presented in the companion paper (Halas et al. 2004) successfully predicts the qualitative response of pigs to a wide range of variation in nutrient composition. Consequently, the model can be applied to develop feeding strategies to optimise pig production, keeping in mind the restrictions under which it can be applied (see Halas et al. 2004). The model predicts the amount and chemical composition of different body parts, such as lean meat, backfat and organs. For this reason, the model enables prediction of the slaughter performance and also provides a first attempt to simulation of important aspects of meat quality. It simulates the influences of differences in energy sources on energy utilisation in the body and the fat:protein ratio in the meat. However, that prediction should be evaluated with experimental data. With further studies, the model can be improved, especially regarding the rates of protein and energy metabolism in different genotypes.

\section{Acknowledgements}

One of the authors (V. H.) received a Hungarian National Eötvös Scholarship for 4 months from the Hungarian Scholarship Board and a Marie Curie Host Fellowship for 3 months from the European Commission Research Directorates to work at Animal Nutrition Group of Wageningen University.

\section{References}

Beech SA, Elliott R \& Batterham ES (1991) Sucrose as an energy source for growing pigs: energy utilisation for protein deposition. Anim Prod 52, 535-543.

Bibby J \& Toutenburg H (1977) Prediction and Improved Estimation in Linear Models. Chichester, Sussex: John Wiley \& Sons.

Bikker P, Karabinas V, Versegen MWA \& Campbell RG (1995) Protein and lipid accretion in body components of growing gilts
$(20-45 \mathrm{~kg})$ as affected by energy intake. J Anim Sci 73, 2355-2363.

Bikker P, Verstegen MWA \& Campbell RG (1996a) Performance and body composition of fattening gilts $(45-85 \mathrm{~kg})$ as affected by energy intake and nutrition in early life. 1 . Protein and lipid accretion in body components. J Anim Sci $\mathbf{7 4 ,}$ 817-826.

Bikker P, Verstegen MWA, Campbell RG \& Kemo B (1994) Digestible lysine requirement of gilts with high genetic potential for lean gain, in relation to the level of energy intake. J Anim Sci 72, 1744-1753.

Bikker P, Verstegen MWA, Kemp B \& Bosch MW (1996b) Performance and body composition of fattening gilts $(45-85 \mathrm{~kg})$ as affected by energy intake and nutrition in early life. 1. Growth of the body and body compartments. J Anim Sci 74, 806-816.

Black JL (1995) Testing and evaluation of models. In Modelling Growth in the Pig, pp. 23-31 [PJ Moughan, MWA Verstegen and MI Visser-Reyneveld, editors]. Wageningen: Wageningen Pers.

Chen HY, Lewis AJ, Miller PS \& Yen JT (1999) The effect of excess protein on growth performance and protein metabolism of finishing barrows and gilts. J Anim Sci 77, 3238-3247.

Chwalibog A, Jakobsen K, Henckel S \& Thorbek G (1992) Estimation of quantitative oxidation and fat retention from carbohydrate, protein and fat in growing pigs. J Anim Physiol Anim Nutr 68, 123-135.

Chwalibog A, Jakobsen K \& Thorbek G (2001) Quantification of energy transfer from carbohydrate to fat metabolism in growing pigs. In Energy Metabolism in Animals. European Association of Animal Production Publication no. 103, pp. 225-228. Snekkersten: EAAP.

Central Veevoeder Bureau (1998) Central Veevoeder Bureau. Lelystad:.

Gerrits WJJ, Dijkstra J \& Frances J (1997) Evaluation of a model integrating protein and energy metabolism in preruminant calves. J Nutr 127, 1243-1252.

Halas V, Dijkstra J, Babinszky L, Verstegen MWA \& Gerrits WJJ (2004) Modelling of nutrient partitioning in growing pigs to predict their anatomical body composition. 1. Model description. Br J Nutr 92, 707-723.

Lizardo R, van Milgen J, Mourot J, Noblet J \& Bonneau M (2002) A nutritional model of fatty acid composition in the growingfinishing pigs. Livest Prod Sci 75, 167-182.

Noblet J, Henry Y \& Dubois S (1987) Effect of protein and lysine levels in the diet on body gain composition and energy utilisation in growing pigs. J Anim Sci $\mathbf{6 5}, 717-726$.

Van Lunen TA \& Cole DJA (1996) The effect of lysine/digestible energy ratio on growth performance and nitrogen deposition of hybrid boars, gilts and castrated male pigs. Anim Sci 63, $465-475$.

Whittemore CT \& Fawcett RH (1976) Theoretical aspects of a flexible model to simulate protein and lipid growth in pigs. Anim Prod 22, 87-96. 